\title{
APLIKASI INVESTASI DALAM MENSEJAHTERAKAN MASYARAKAT USAHA KELAS MENENGAH BERBASIS WEB
}

\author{
Teguh Kurniawan 1 \\ Prodi Sistem Informasi \\ Universitas Islam Negeri Sumatera Utara \\ Jln.William Iskandar Muda Pasar V Medan Estate \\ Sumatera Utara, Indonesia \\ teguhkrniawan@gmail.com ${ }^{1}$
}

\begin{abstract}
Abstrak
Abstrak - Indonesia merupakan salah satu negara dengan ingkat pengangguran tertinggi di Asia. Ketidakseimbangan antara banyak nya jumlah penduduk dengan lapangan perkerjaan yang tersedia menjadi faktor penyebab terjadinya angka pengangguran. Berwirausaha merupakan salah satu solusi untuk menambah penghasilan masyarakat, akan tetapi para masyarakat usaha kelas menengah sering kekurangan modal, untuk itulah dibuat suatu aplikasi yang tujuan nya mempertemukan para masyarakat yang berwirausaha usaha kelas menengah ini dengan para investor melalui sebuah situs yang dibangun menggunakan algoritmaalgoritma sederhana. Dengan adanya wadah ini para pengusaha usaha kelas menengah tidak akan kekurangan modal serta para investor pun lebih leluasa dalam menginvestasikan dana.
\end{abstract}

Kata Kunci : Usaha Kelas Menengah , Situs, Investor

\section{Pendahuluan}

Dalam setahun terakhir, pengangguran bertambah 10 ribu orang, sementara TPT turun sebesar 0,11 poin. Dilihat dari tingkat pendidikan, TPT untuk Sekolah Menengah Kejuruan (SMK) paling tinggi diantara tingkat pendidikan lain, yaitu sebesar 11,41 persen. (Data statistik tahun 2017 www.bps.go.id)

Hal ini tentunya menjadi masalah bagi negeri ini jika pengangguran dianggap sebelah mata oleh pemerintah, akan 
banyak rakyat yang tidak sejahtera jika masalah ini terus dibiarkan. Untuk itulah pemerintah memeberikan saran kepada para masyarakat untuk membuat lapangan perkerjaan sendiri dengan berwirausaha salah satunya ialah dengan membangun usaha kelas menengah.

Banyak masyarakat yang ingin membangun usaha kelas menengah hanya saja terdapat kendala dalam membangunnya, yaitu modal atau dana untuk membangun usaha itu sendiri. Tidak adanya barang atau sesuatu yang bisa menjadi jaminan ketika meminjam disuatu instansi peminjaman uang atau modal sehingga banyak masyarakat indonesia yang memutuskan untuk tidak membangun usaha kelas menengah atau mengembangkan usaha kelas menengah yang telah dibangun.

Disatu sisi ada juga mereka orang-orang yang memiliki penghasilan lebih yang ingin berinvestasi didunia bisnis akan tetapi tidak tahu kemana harus memulai langkah investasi ini, maka dua kasus ini merupakan dua hal yang bisa diintegrasikan agar kedua pihak bisa mendapatkan keuntungan.

Dengan memanfaatkan kemajuan teknologi yang ada muncul sebuah solusi untuk mewujudkan keinginan masyarakat yang ingin terjun kedunia usaha kelas menengah dan untuk membantu investor yang baru ingin menginvestasikan dananya melalui sebuah aplikasi berbasis web, dimana pada aplikasi ini mereka bisa saling berinteraksi, berkomunikasi, dan berkeja sama sehingga diharapkan kedua belah pihak memperoleh keuntungan yang sama dan ikut serta menurunkan tingkat persentase penganggura di Indonesia.

\section{Kajian Teori}

\section{a. WEB}

Web Merupakan suatu ruang informasi dimana sumber sumber daya yang berguna diidentikaasi oleh pengenal global yang disebut uniform resource identifie. Web sendiri terbagi menjadi dua yaitu web statis dan web dinamis, web statis adalah website dimana penggunannya tidak bisa mengubah konten dari web tersebut secara langsung menggunakan browser, sedangkan web dinamis adalah website yang bisa langsung diubah oleh 
penggunannya melalui browser dan biasanya terhubung melalui database. Dan dalam tulisan ini penulis menggunakan web dinamis dalam melakukan penelitiannya.

\section{b. Database}

Database atau basis data adalaah kumpulan informasi yang disimpan didalam komputer secara sistematik sehingga dapat diperiksa menggunakan suatu program komputer untuk memperoleh informasi dari basis data tersebut. Perangkat lunak yang digunakan untuk mengelola dan memanggil kueri (query).

\section{c. PHP}

PHP merupakan bahasa pemograman yang disebut sebagai bahasa scripting dalam arti PHP merupakan bahasa pemograman yang ditempelkan / embedded pada bahasa atau aplikasi lain. PHP sudah menjadi standar bahasa populer dalam dunia website masa kini sehingga penulis memutuskan untuk menjadikan PHP sebagai salah satu objek pendukung penelitian pembuatan website ini.

\section{Metode Penelitian}

Dalam penelitian ini penulis menggunakan metode kuesioner atau angket dengan memanfaatkan layanan penyedia google forms ,pada angket tersebut diberikan beberapa pertanyaan yang bersangkutan dengan penelitian ini. Menurut Sugiyono $(2008,199)$ "Angket atau kuesioner merupakan teknik pemgumpulan data yang dilakukan dengan cara memberikan seperangkat pertanyaan atau pernyaan kepada responden untuk dijawab"

\section{Teknik Pengumpulan dan Sumber Data}

\begin{tabular}{|l|l|l|l|}
\hline No & Pertanyaan & Ya & Tidak \\
\hline 1. & $\begin{array}{l}\text { Apakah anda ingin terjun kedunia usaha kelas } \\
\text { menengah? }\end{array}$ & & \\
\hline 2. & $\begin{array}{l}\text { Apakah Anda kekurangan / tidak memiliki } \\
\text { modal dalam membangun usaha kelas } \\
\text { menengah? }\end{array}$ & & \\
\hline
\end{tabular}




\begin{tabular}{|l|l|l|l|}
\hline 3. & $\begin{array}{l}\text { Apakah anda yakin UKM bisa membuat } \\
\text { kehidupan anda lebih sejahtera? }\end{array}$ & & \\
\hline 4. & Apakah anda ingin menjadi investor? & & \\
\hline 5. & $\begin{array}{l}\text { Apakah anda ingin bertemu dengan para } \\
\text { investor untuk kemajuan usaha anda }\end{array}$ & & \\
\hline 6. & $\begin{array}{l}\text { Apakah anda ingin menanam modal ke } \\
\text { masyarakat yang berada di rana UKM? }\end{array}$ & & \\
\hline 7. & $\begin{array}{l}\text { Apakah diperkukan sebuah solusi baru } \\
\text { berbasis teknologi untuk mempertemukan } \\
\text { pengusaha UKM dengan investor? }\end{array}$ & & \\
\hline
\end{tabular}

\begin{tabular}{|c|c|c|c|c|c|c|c|c|c|c|c|c|c|c|c|c|c|c|c|c|c|c|c|c|c|}
\hline \multirow[b]{2}{*}{ Pertanyaan } & \multicolumn{25}{|c|}{ Resoneden } \\
\hline & $\begin{array}{ll}1 \\
\end{array}$ & & & & & & & & & & 14 & 15 & 16 & & & & & & & & & & & 28 & \begin{tabular}{l|l}
29 & 30 \\
\end{tabular} \\
\hline 1 & 1 & & 1 & & 1 & 1 & & 1 & 1 & 1 & 1 & 1 & 1 & 1 & 1 & & & 1 & 1 & 1 & 0 & 1 & 1 & 1 & \begin{tabular}{l|l}
1 & 1 \\
\end{tabular} \\
\hline 2 & 1 . & & 1 & & 1 & 1 & 1. & 1 & 1 & 1 & 1 & 1 & 1 & 0 & 0 & & 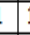 & $1+$ & 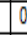 & 1 & 1 & 1 & 1 & 1 & 1 \\
\hline 3 & 1 & 11 & 1 & & 1 & 1 & $1]$ & 0 & 1 & 1 & 1 & 1 & 1 & 1 & 1 & 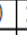 & $y$ & 1 & 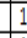 & 1 & 1 & 1 & & 1 & 1 \\
\hline 4 & 1 & & & & & & & 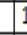 & 1 & 1 & 1 & 1 & 1 & 1 & 1 & & & 1 & 1 & 1 & 1 & 1 & & 1 & \begin{tabular}{l|l}
1 & 1 \\
\end{tabular} \\
\hline 5 & 1 & & 1 & & & & & & 1 & 1 & 1 & 1 & 1 & 1 & 1 & & & 1 & 1 & 1 & 0 & 1 & & 1 & \begin{tabular}{l|l}
1 & 1 \\
\end{tabular} \\
\hline 6 & 1 & & & & & & & & 1 & 1 & 1 & 1 & 1 & 1 & 1 & & 1 & 10 & 1 & 1 & 1 & 1 & 1 & 0 & \begin{tabular}{l|l}
1 & 1 \\
\end{tabular} \\
\hline 7 & \begin{tabular}{|l|}
1 \\
\end{tabular} & & & & & & & & & & & & & & & & & & & & & & & & \begin{tabular}{l|l}
1 & 1 \\
\end{tabular} \\
\hline
\end{tabular}

Keterangan: 1. Ya

0.Tidal

Dengan Tabel diatas, penulis mengumpulkan sebanyak 30 sampling dari respnden diwilayah yang berbeda beda dan memperoleh hasil bahwa diperlukannya sebuah situs sebagai wadah berjumpanya investor dengan pengusaha UKM.

\section{Hasil dan Pembahasan}

\section{a. Cara Kerja Sistem}

Terdapat dua aktivitas yang bisa dilakukan oleh user, yang pertama sebagai pengusaha yang ingin mencari modal dan user yang masuk sebagai investor yang ingin menamkan modal. Sistem ini dikembangkan melalui basis website yang sudah sedemikian 
Aplikasi Investasi Dalam Mensejahterakan Masyarakat Usaha Kelas Menengah Berbasis WEB

rupa diatur agar para investor bisa berinteraksi dengan para masyarakat yang terjun ke dunia usaha kelas menengah.

\section{b. Tampilan Sistem}

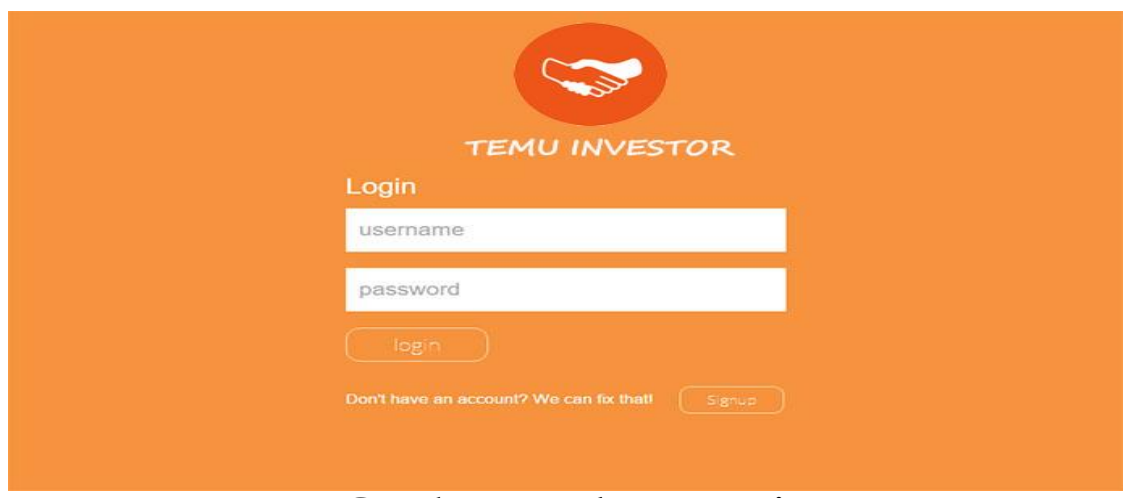

\section{Gambar 1. Halaman Login}

Pada gambar 1 user dapat mendaftar dan login kedalam situs agar bisa memakai layanan situs untuk mempertemukan investor dengan pengusaha usaha kelas menengah yang ingin membangun usahannya atau mengembangkan usahannya.

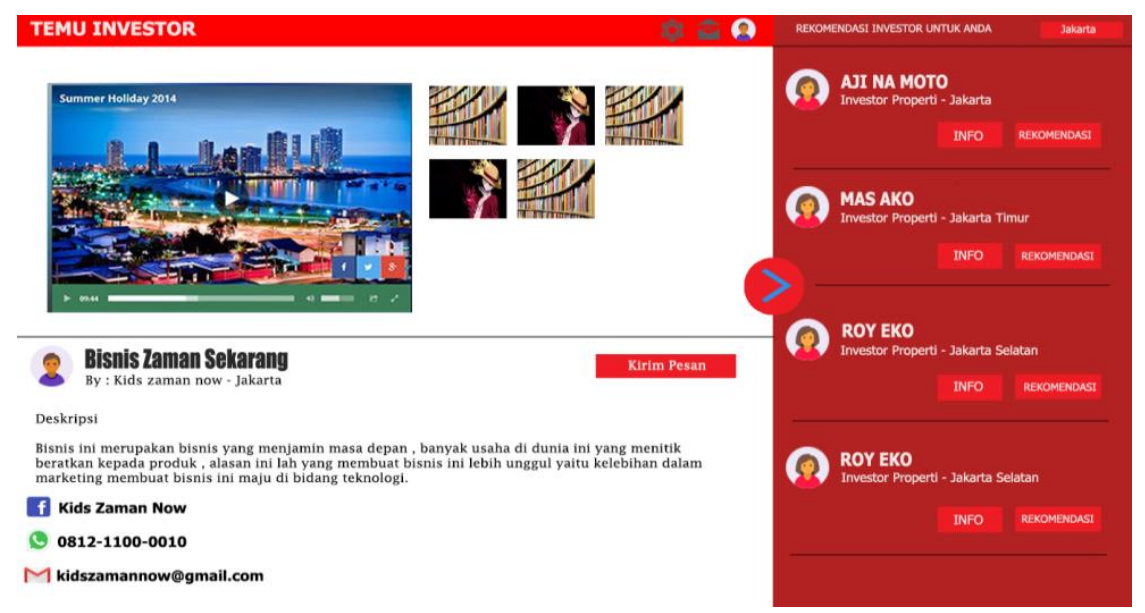

Gambar 2. Halaman Beranda User 
Pada gambar2 merupakan tampilan pengguna untuk user pengusaha yang akan merekomendasikan dirinya kepada investor , dan user juga bisa mengupload video atau gambar terkait usaha yang akan mereka kembangkan.

\section{Kesimpulan}

Rancangan aplikasi ini diharapkan akan meningkatkan kesejahteraan masyarakat khususnya yang berada didalam dunia bisnis usaha kelas menengah serta aplikasi ini diharapkan agar negara Indonesia bisa menurunkan persentase angka tingkat pengangguran yang bisa dibilang tinggi.

\section{Daftar Pustaka}

Damanik, Ericsons. Pengertian-pengertian dan Info. http://pengertian-pengertianinfo.blogspot.co.id/2016/01/pengertian-dan-jenis-jeniskuesioner.html, 2014.

Sakur, Stendy B. 2010. PHP5 Pemograman Berorientasi Objek Konsep dan Implementasi. Yogjakarta : Penerbit Abadi.

Mahyuzir, T.D.1998. Rekayasa Perangkat Lunak, Yogyakarta : Andi Offset

Surajino, S.H.R. 2004, Pembelajaran Berbas is Web: Suatu Tujuan dari aspek Kognitif, Makalah Lokakarya metode Pembelajaran Berbasis Web-Departemen Teknik Penerbangan ITB, Bandung 1 Oktober 2004 